\title{
Perancangan Materi Edukasi Visual Pola Konsumsi Sehat Kopi
}

\author{
Hari Ardiansyah, Irene Erika Listya, dan Okky Nugraha Pratama \\ STIKOM London School of Public Relations \\ Email : harijawak@gmail.com, erikagero96@gmail.com, \\ okkynugrahapratama@gmail.com
}

\begin{abstract}
ABSTRAK
Kopi telah menjadi bagian dari gaya hidup masyarakat dan ternyata kopi mengandung banyak khasiat yang baik untuk kesehatan bila dikonsumsi secara baik dan benar, namun masyarakat Indonesia belum sepenuhnya teredukasi mengenai cara minum kopi yang baik dan benar. Sehingga diperlukan materi edukasi visual yang efektif dan mampu meliputi semua tentang konsumsi kopi secara sehat serta manfaat dan dampak kopi untuk kesehatan. Dalam mendisain menggunakan proses disain komunikasi visual yang terdapat 9 langkah, yaitu riset, analisis, sintesis, karakteristik, strategi komunikasi, value-added, pemilihan media, visualisasi, dan produksi. Dengan materi edukasi visual pola konsumsi sehat kopi diharapkan dapat meningkatkan kesadaran masyarakat atau penikmat kopi agar menyadari pada pola konsumsi kopi secara sehat,
\end{abstract}

Kata kunci: Edukasi, kopi, kesehatan, disain komunikasi visual.

\begin{abstract}
Coffee has become a part of people's lifestyles and it turns out that coffee contains many benefits that are good for health if consumed properly, but the Indonesian people have not been fully educated on how to drink coffee that is good and right. It needed effective and capable visual education material covering all about healthy coffee consumption and the benefits and effects of coffee for health. In designing using a visual communication design process that has 9 steps, namely research, analysis, synthesis, characteristics, communication strategies, value-added, media selection, visualization, and production. With visual education material, healthy consumption patterns of coffee are expected to increase public awareness or coffee connoisseurs to be aware of healthy coffee consumption patterns.
\end{abstract}

Keywords: Education, coffee, health, visual communication design. 


\section{PENDAHULUAN}

Kopi telah menjadi bagian dari gaya hidup masyarakat, tidak hanya kalangan orang tua saja yang menikmati akan tetapi kalangan anak muda juga sekarang sudah banyak yang menikmati kopi layanya kalangan orang tua. Menurut Mardana kopi dapat disimpulkan sebagai sebuah jenis minuman yang berasal dari hasil pengolahan biji kopi yang telah dipanggang dan digiling menjadi bubuk kopi. Rasa serta aroma kopi yang khas dan berbeda dari minuman lain dapat menjadikannya sebagai minuman yang banyak dipilih untuk segala suasana (2016, Oktober 28, para.1).

Selain menjadi bagian dari gaya hidup, ternyata kopi mengandung banyak khasiat yang baik untuk kesehatan bila dikonsumsi secara baik dan benar. Namun menurut Media Otten Coffe menyatakan bahwa Indonesia merupakan salah satu negara penghasil kopi terbesar di dunia, namun masyarakat Indonesia belum sepenuhnya teredukasi mengenai cara minum kopi yang baik dan benar (Yuliandri, 2015, November 2015. para.1).

Untuk itu pengkarya akan membuat materi edukasi visual tentang konsumsi kopi secara sehat serta manfaat dan dampak kopi untuk kesehatan. Materi edukasi visual ini akan disasarkan kepada semua kalangan yang bergiat dalam kopi diantaranya Barista dan Penikmat Kopi.

Barista diambil sebagai sasaran khalayak dikarenakan sesuai data yang telah kami ambil dari narasumber bahwa Barista merupakan tangan terakhir yang memberikan kopi kepada penikmat kopi, tentunya Barista harus diedukasi mengenai bagaimana minum kopi yang baik dan benar serta manfaat kopi bagi kesehatan karena pada dasarnya penikmat kopi sering berinteraksi kepada Barista.
Kemudian, Penikmat Kopi diambil juga sebagai sasaran karena penikmat kopi sendiri mulai dari kalangan pelajar, mahasiswa, hingga karyawan. Melalui observasi ke coffeeshop yang telah pengkarya lakukan, kami melihat beberapa pengunjung di coffeeshop diantaranya beberapa pelajar yang sedang mengerjakan tugas sekolah, kemudian beberapa mahasiswa yang sedang mengerjakan tugas ataupun skripsi hingga kalangan karyawan atau pekerja yang sedang melakukan meeting. Pemilihan sasaran khalayak untuk materi edukasi visual ini harapannya agar akan memberikan pengetahuan bagi masyarakat Indonesia.

Tedapat lembaga yang mendukung dalam pembuatan materi edukasi visual ini mengenai pola konsumsi sehat kopi diantaranya Kementrian Kesehatan Republik Indonesia dan Lembaga Badan Ekonomi Kreatif Republik Indonesia (Bekraf). Dimana Bekraf RI telah banyak mendukung perkembangan kopi di Indonesia salah satunya terdapat campaign "Kopi itu digiling, bukan digunting". Dengan adanya materi edukasi visual ini harapannya agar memberikan pengetahuan lebih kepada penikmat kopi di Indonesia.

\section{METODE PENELITIAN}

\section{Materi Edukasi Visual}

Salah satu pendekatan edukasi yang dapat dilakukan untuk mengedukasi masyarakat dengan mengatur pola konsumsi kopi secara sehat salah satunya adalah dengan menggunakan pendekatan desain komunikasi visual

\section{Desain Komunikasi Visual}

Salah satu pendekatan edukasi yang dapat dilakukan untuk mengedukasi masyarakat dengan mengatur pola konsumsi kopi secara sehat salah satunya adalah dengan menggunakan pendekatan desain komunikasi 
visual. Menurut Kusrianto Desain Komunikasi Visual adalah suatu disiplin ilmu yang bertujuan mempelajari konsepkonsep komunikasi serta ungkapan kreatif melalui berbagai media untuk menyampaikan pesan dan gagasan secara visual dengan mengelola elemen-elemen grafis yang berupa bentuk dan gambar, tatanan huruf, serta komposisi warna serta layout (tata letak atau perwajahan). Dengan demikian, gagasan bisa diterima oleh orang atau kelompok yang menjadi sasaran penerima pesan $(2007$, p.2).

\section{Langkah-langkah kerja}

Dalam langkah-langkah perancangan karya, pengkarya menggunakan proses desai komunikasi visual yang dianut oleh Savanayong. Dalam buku Desain Komunikasi Visual Terpadu (Savanayong, 2006, p. 3), proses desain komunikasi visual terdapat 9 langkah, diantaranya:

\section{Riset}

Tahap awal dalam proses perancangan materi edukasi adalah melakukan riset. Riset dilakukan untuk menentukan inti permasalahan dan memfokuskan tujuan pengkarya dalam pembuatan karya. Dalam melakukn riset ini pengkarya akan mengumpulan data yang berhubungan dengan nilai kandungan dan kesehatan dari kopi. Riset dilakukan dengan 3 cara, yaitu: Wawancara, Observasi dan Studi Pustaka.

\section{A. Wawancara}

Wawancara pertama dilakukan dengan narasumber yakni Zafitra Indra dari Deputi Riset dan Edukasi. Hasil Wawancara salah satunya ialah Bekraf saat ini mengadakan pelatihan barista dimana program tersebut bernama "Racik Kopi", dimana kegiatan ini merupakan pelatihan kepada barista sebelum melakukan proses sertifikasi standarisasi barista. Dalam setiap metode brewing, barista sangat berpengaruh untuk menciptakan cita rasa dalam membuat kopi, metode brewing terdapat dua cara yaitu manual brewing dan modern brewing. Untuk menciptakan cita rasa kopi yang nikmat terdapat dua hal yang berpengaruh yakni suhu dan ekstraksi kepadatan kopi.

Wawancara kedua dilakukan dengan narasumber yaitu petani kopi asal Lampung Barat yaitu Hermawan. Hasil wawancara salah satunya ialah Kelompok petani masih merasa memiliki masalah dimana membutuhkan suatu kelompok untuk mengedukasi tentang manfaat kopi. Pekerjaan kami hanya terbatas dari produksi kopi meliputi pemetikan, pengelolaan kebun, pengolahan paska panen hingga sampai dicangkir, karena ingin mengutamakan kualitas kopi.

Wawancara ketiga dilakukan dengan narasumber yaitu media @bicarakopi. Hasil wawancara pertama, Biji kopi harus disimpan ditempat yang tidak terkena sinar matahari langsung. Paling aman kopi disimpan dikemasan yang memiliki katup atau di toples. Kemudian kedua Suhu ideal air untuk menyeduh kopi adalah 85 hingga 94 derajat celcius. dan ketiga menyarankan untuk mengonsumsi 2 hingga 3 gelas per hari.

\section{B. Observasi}

Observasi dilakukan dibeberapa kedai kopi yang bertempat disekitaran Jabodetabek. Observasi ini dilakukan untuk melihat perilaku orang-orang yang sedang berkunjung di kedai kopi dan melihat denah kedai kopi. Observasi ini dilakukan dibeberapa tempat salah satunya adalah filosofi kopi.

Seni kanvas yang menjadi pajangan didalam coffeeshop Filosofi Kopi berhubungan dengan kopi, namun masih belum terlihat mengenai informasi untuk mengedukasi pola konsumsi kopi secara sehat. Oleh karena itu pengkarya merasa ada peluang untuk peletakan materi edukasi pola konsumsi secara sehat ini di coffeeshop. 


\section{Studi Pustaka}

Kemudian pengkarya melakukan studi pustaka sebagai pelengkap dari data-data yang telah dikumpulkan. Data pelengkap tersebut diantaranya adalah cara memilih biji yang baik dan manfaat kopi apabila dikonsumsi secara sehat.

\section{Analisis}

Dalam tahap ini pengkarya menganalisa dari data yang telah dikumpulkan dan akan melakukan verifikasi untuk diperoleh kebenarannya.

Untuk itu pengkarya bersama akan bersama lembaga yang memahami tentang gizi dan kesehatan untuk menganalisa dan memverifikasi data yang dikumpulkan terkait nilai kandungan gizi dari kopi dan pola konsumsinya kopi yang sehat. Lembaga yang diyakini oleh pengkarya adalah Kementrian Kesehatan RI dalam Deputi Gizi Masyarakat.

Dari data yang telah dikumpulkan, dari pihak Kementrian Kesehatan RI telah menguji kebenerannya dan menyatakan bahwa yang dikumpulkan adalah benar sesuai dengan pola konsumsi kopi secara sehat. Kemenkes RI juga menambahkan informasi dengan menekankan pada mengonsumsi kopi tanpa gula dan tidak mengonsumsi makanan pendamping yang mengandung kadar gula yang tinggi pada saat bersamaan dengan mengonsumsi kopi.

Berdasarkan diskusi pengkarya dengan narasumber dan penganalisa data maka menghasilkan 4 konten yang akan dimasukkan ke dalam 4 materi poster dimana poster sebagai materi utama dalam perancangan materi edukasi ini, diantaranya:

1. Poster pertama akan diisi dengan ajakan mengonsumsi kopi dengan baik.

2. Poster kedua akan diisi bagaimana memilih biji kopi yang baik.

3. Poster ketiga akan diisi dengan konten barista dalam membuat kopi yang benar dan baik dan takaran yang benar pada secangkir kopi.

4. Poster empat akan diisi dengan konten mengonsumsi kopi diwaktu yang tepat sehingga memiliki manfaat bila mengonsumsi kopi dengan benar dan sehat.

\section{Sintesis}

Dalam tahap ini, pengkarya akan menentukan sasaran khalayak dari segi geografis, demografis, dan psikografis. Tahapan ini bertujuan untuk menenentukan kepada siapalah pengkarya berkomunikasi serta memberikan informasi pola konsumsi kopi secara sehat. Untuk memenuhi keberhasilan dari materi edukasi ini, pengkarya akan menentukan target audiens dari segi geografis, demografis, dan psikografis melalui pengumpulan data dengan wawancara dan terutama observasi yang dilakukan oleh pengkarya melalui kunjungan ke beberapa kedai kopi.

Geografis:

Wilayah yang dianggap sebagai trendsetter. Wilayah trendsetter merupakan wilayah panutan yang akan memberikan pengaruh untuk ditiirukan oleh wilayah lainnya terutama terutama kota besar lainnya seperti: Bali, Jogja dan Medan. Wilayah yang dianggap sebagai trendsetter. yakni DKI Jakarta.

Demografis:

Usia: 17-25 tahun

Jenis Kelamin: Pria dan Wanita

Profesi: Pelajar, Mahasiswa, dan Barista

Penentuan target audiens secara demografis berdasarkan observasi pengkarya di coffeeshop. Dimana pada observasi tersebut pengkarya berbincang dengan penikmat kopi. Dari data observasi, target audiens pada perancangan ini adalah berumur 17-25 tahun. 
Psikografis:

- Orang-orang yang kurang mempedulikan kesehatannya.

- Orang-orang yang suka minum kopi di coffeeshop.

- Penikmat kopi.

- Pecandu kopi.

Penentuan target audiens secara geografis berdasarkan observasi pengkarya di coffeeshop dengan melihat perilaku penikmat dan pecandu kopi.

\section{Karakteristik}

Karakteristik yang digunakan dalam desain yang akan dibuat oleh pengkarya terdapat beberapa poin agar pesan yang terkandung dalam sebuah perancangan materi edukasi dapat dimengerti dan dipahami oleh masyarakat, yaitu:

\section{1.) Pokok / Big Idea}

Dalam pembuatan materi edukasinya, pengkarya mengolaborasikan Kemenkes RI dengan BEKRAF RI untuk memberikan kekompakan dan keyakinan kepada masyarakat bahwa institusi terkait memperhatikan masyarakat dalam mengonsumsi kopi secara sehat.

Tema yang dipilih untuk mengangkat sebuah materi edukasi dari pola konsumsi kopi ini adalah penyampaian pesan melalui gaya formal digabungan dengan pesan visual dengan gaya informal dengan menggunakan ilustrasi berjenis hand drawing dan vector dipadukan dengan ilustrasi beraliran hipster sehingga mumunculkan gaya layout yang berjenis Flat Design. Flat Design sendiri merupakan gaya desain yang paling banyak digunakan dan populer pada saat ini, karena gaya desain ini menggunakan warna yang kalem dan enak dipandang (Ilmunesia, 2017)
2. Pesan

Menyampaikan informasi mengenai pola konsumsi kopi secara sehat dengan bentuk bahasa dan tipografi.

3. Pesan Visual

Pesan visual merupakan salah satu daya tarik dari materi edukasi dan menampilkan karakter dimana pada perancangan ini akan menampilkan karakteristik dari kopi.

\section{Strategi Komunikasi}

Untuk mencapai tujuan yang diinginkan, pengkarya menggunakan strategi komunikasi yang tepat sesuai dengan konsep dan karakter mengenai kopi. Strategi komunikasi tersebut dilakukan dengan cara menetapkan strategi yang efektif dimana terdapat dua poin dalam menetapkan strategi komunikasi yaitu:

1.) Isi Pesan

Pesan utama yang ingin disampaikan yaitu menginformasikan kepada masyarakat bahwa kopi itu tidak identik dengan kafein yang berdampak negatif saja, melainkan kopi dapat berdampak positif apabila mengonsumsinya dengan benar dan teratur.

2.) Bentuk Pesan

Headline yang digunakan pengkarya harus bersifat menarik dan informatif agar audiens yang melihat dapat memahami keseluruhan dari materi edukasi hingga membaca detailnya. Headline sangat berperan penting karena headline akan selalu menjadi pertama yang dipandang oleh masyarakat, oleh karena itu font untuk headline akan lebih besar daripada konten teks yang lainnya.

\section{Value-added}

Value added dalam sebuah materi edukasi tentang kopi adalah sebuah tuntutan atau tantangan nilai lebih yang dimiliki dalam materi edukasi untuk menarik perhatian sasaran. Materi edukasi yang digunakan biasanya harus memiliki unsur keunikan agar khalayak menjadi tertarik. 
Value added dalam perancangan materi edukasi ini terdapat tiga keunikan, sebagai berikut:

1. Ilustrasi bergaya hipster meskipun nuansa dari layout materi edukasi ini bergaya formal.

2. Tipografi bergaya hipster meskipun pesan yang disampaikan terkesan kaku karena membawa institusi pemerintah.

3. Fotografi akan menggunakan teknik cropping dipadukan dengan teknik gradasi sehingga memunculkan kesan yang halus dan tisak kasar.

\section{Pemilihan media}

Untuk mencapai tujuan dari perancangan materi edukasi ini, maka digunakan strategi pemilihan media yang mampu menjangkau masyarakat adapun media edukasi yang akan digunakan, yaitu materi edukasi utama dan materi edukasi pelengkap.

Media edukasi yang akan digunakan yaitu:

\section{Poster}

Poster adalah gambar pada selembar kertas berukuran besar yang digantung atau ditempel dipermukaan lain. Poster merupakan alat mengiklankan sesuatu, sebagai alat propaganda, dan protes, serta maksudmaksud lain untuk menyampaikan berbagai pesan (Kusrianto, 2007, p.334).

2. Flyer

Flyer biasanya hanya berupa cetakan satu muka. Kualitas cetakannya tidak harus bagus, bahkan seringkali berkualitas seadanya, sebab dibuat dalam jumlah besar dan berbiaya murah karena sudah diperkirakan bahwa banyak diantara flyer akan terbuang dalam waktu relatif singkat berganti fungsi menjadi sampah. Walaupun begitu, flyer yang baik akan didesain dengan memperhatikan kaidah yang menarik untuk dilihat dan dibaca (Shimp, 2003).
3. Foodtruck

Menurut Farkas a food truck is a mobile, miniature commercial kitchen that must meet the state sanitation requirements of a brick-and-mortar restaurant, as well as be in compliance with additional local ordinance (2013, p.2).

Menurut Palupi Foodtruck digambarkan sebagai sebuah truk yang digunakan untuk media pemasaran produk makanan tertentu dengan berbagai kriteria tertentu juga (2017, p.10),.

4. Media Sosial Instagram

Instagram adalah media yang memberi kemudahan cara berbagi secara online oleh foto-foto, video dan juga layanan jejaring sosial yang dapat digunakan pengguna untuk mengambil dan membagi ke teman mereka (Budiargo, 2015, p.48).

5. Merchandise

Menurut Rainer merchandise adalah pernak-pernik yang sering kita jumpai dan dipakai oleh banyak orang diberbagai kesempatan (2017, para. 4). Contohnya adalah pada kaos polos dengan sablon atau bordir yang ada gambar dan logo perusahaan, atau bisa juga pada payung, jam dinding, flashdisk, pulpen, buku, cangkir kopi dan lainnya. Merchandise yang akan digunakan pengkarya ialah cangkir kopi.

\section{Visualisasi}

Sebelum pengkarya mendesain materi edukasi pola konsumsi kopi secara sehat, pengkarya akan membuat sketsa dengan menggunakan kertas dan pensil yang bertujuan agar memperoleh bayangan untuk meletakkan objek visual dan konten-konten yang terdapat pada materi edukasi.

\section{Produksi}

Tahapan akhir dari proses perancangan materi edukasi untuk pola konsumsi kopi secara sehat adalah membuat dummy dari hasil sketsa yang telah dibuat. 


\section{HASIL DAN PEMBAHASAN}

Berikut ini adalah hasil akhir dari materi edukasi yang telah dibuat:

1.) Poster
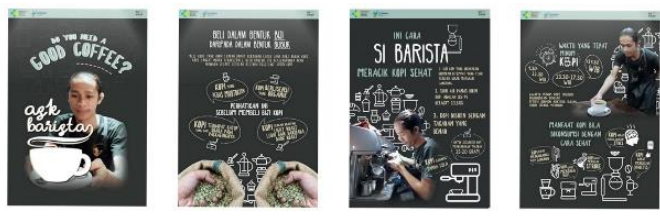

Gambar 1. Final Desain untuk Poster

Nantinya 4 seri poster ini akan diletakkan di bagian pengambilan order di coffeeshop.

2.) Flyer

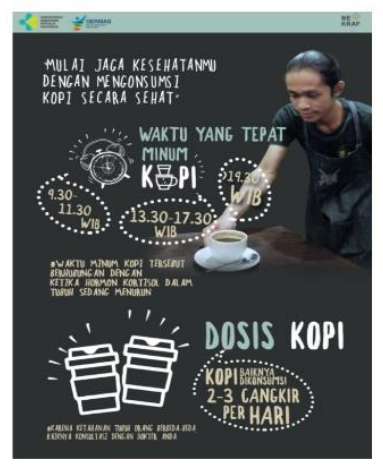

Gambar 2. Final Desain untuk Flyer

Nantinya flyer poster diletakkan diatas meja pada gerai pemesanan yang terdapat di coffeeshop.

3.) Foodtruck

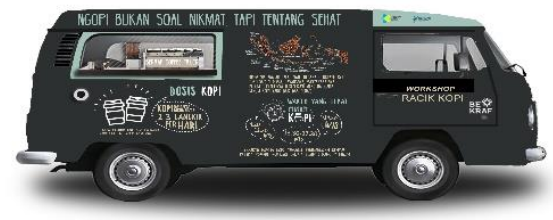

Gambar 3. Final Desain untuk Foodtruck

Foodtruck ini yang nantinya akan menjadi fasilitas yang disediakan oleh Kemenkes RI bekerja sama dengan BEKRAF RI dalam menjalankan workshop "Racik Kopi".

\section{4.) Media Sosial Instagram}
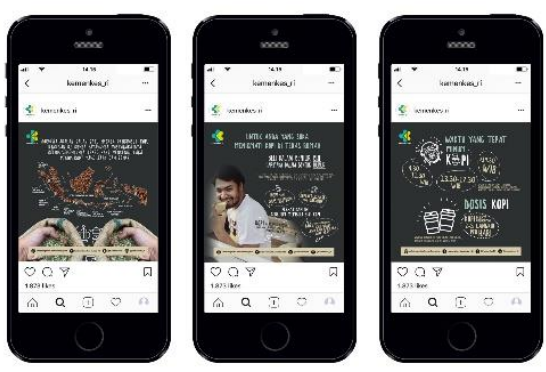

Gambar 4. Final Desain untuk Media Sosial Instagram

Dari gambar diatas menunjukkan bahwa desain untuk media sosial instagram akan diunggah kedalam akun Instagram resmi dari Kemenkes RI.

5.) Merchandise

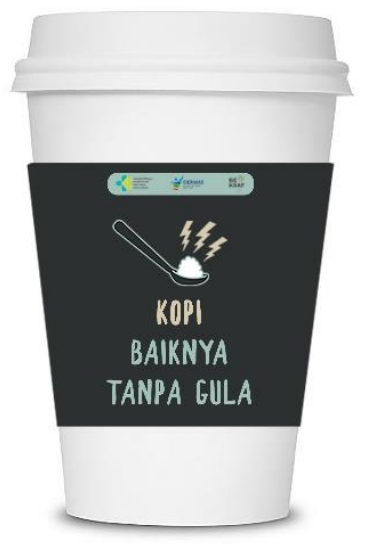

Gambar 5. Final Desain untuk Merchandise

Nantinya gelas merchandise ini akan dibagikan ke beberapa coffeeshop di DKI Jakarta untuk pemesanan yang dibawa pulang atau take away.

\section{KESIMPULAN}

Perancangan materi edukasi pola konsumsi kopi secara sehat memfokuskan pada upaya perubahan perilaku untuk mengonsumsi kopi dengan baik dan benar, 
dengan sasaran khalayak laki-laki dan perempuan berumur 17-25 tahun. Untuk meningkatkan kesadaran masyarakat agar lebih peduli dengan kesehatannya, terutama pada pola konsumsi kopi secara sehat, diperlukan berbagai materi edukasi lanjutan dengan tujuan yang sama dengan perancangan materi edukasi pola konsumsi kopi secara sehat ini.

Karya yang dihasilkan dari perancangan materi edukasi memiliki keunikan dibandingkan materi edukasi yang diterbitkan sebelumnya dimana karya ini menggambarkan karakter kopi yang kuat dapat kita lihat dari ilustrasi hingga tipografi yang ditampilkan. Pada materi edukasi sebelumnya menggambarkan gaya formal sehingga kurangnya muncul ketertarikan untuk melihat, membaca, dan memahaminya.

\section{DAFTAR PUSTAKA}

Budiargo, Dian. 2015. Berkomunikasi ala Net Generation. Jakarta: PT Elex Media Komputindo Kompas Gramedia.

Farkas, B. A., (2013). Elements of an Effective Process for Developing Food Truck Policies for North Carolina Local Governments. University of North Carolina. United States: North Carolina.

Ilmunesia. (2017, August 7). Apa itu Flat Design? - Ilmunesia. Retrieved June 26, 2019, from http://ilmunesia.com/apa-itu-flatdesign/

Mardana, A., (2016, Oktober 28). Kartini : Ketika Minum Kopi Jadi Tren Gaya Hidup Kaum Urban. Diperoleh dari website: http://majalahkartini.co.id/berita/serb a serbi/ketika-minum-kopi-jaditrengaya-hidup-kaum-urban/

Kusrianto, A., (2007). Pengantar Desain
Komunikasi Visual. Yogyakarta: AndiYogyakarta.

Palupi, H. D., (2017). Penerapan Strategi Bauran Pemasaran Usaha Foodtruck di Chip Chop Yogyakarta, Universitas Negeri Yogyakarta, Indonesia.

Rainer, D., (2017, Juni 2). Pengertian Merchandise Fungsi, Jenis, Contoh Lengkap. Diperoleh dari website: http://www.spengetahuan.com/2017/ 06/pengertian-merchandisefungsijenis-contoh-lengkap.html

Savanayong, Y., (2006). Desain Komunikasi Visual Terpadu. Jakarta: Arte Media.

Shimp,T. A., (2003). Periklanan Promosi \& Aspek Tambahan Komunikasi PemasaranTerpadu, Jilid I ( edisi 5), Jakarta: Erlangga.

Yuliandri, M. T., (2015, November 10). Otten Coffee : 4 Hal Yang Perlu diperhatikan Sebelum Membeli Biji Kopi. Diperoleh dari website: https://majalah.ottencoffee.co.id/4hal-yang-perlu-diperhatikansebelummembeli-biji-kopi/ 